\title{
Jockeying for Position in International Sim Card Industry in India
}

\section{Saibal Kuamr Saha*}

Assistant Professor, University of Technology and Management, 4th Floor, Bawri Mansions, Dhankheti, Shillong, Meghalaya, India

\begin{abstract}
With globalization, there has been a rapid increase in international tourism. People from India have been travelling abroad for business, education, medical treatment, holidays etc. When someone goes abroad he/she has to rely on public phones or take a new sim card in that country. Acquiring a new sim card in a foreign country means a large number of paper work and hassles and not to mention the delay. Hence, a pre acquired international sim card has become a much preferred choice for international travelers. Although, there are a number of players in the market in the international sim card business, but some companies are more preferred than the other. This research aims to throw some light in the customer's preferences for choosing an international sim card in West Bengal, India.
\end{abstract}

Keywords: International sim card; Customer preferences; Sim card industry; Forex; Travel

\section{Introduction}

With the growth of Information Technology -IT sector and liberalization in the policies of Foreign Direct Investment - FDI, a number of international companies have set up their units in India. People working in Multi-National Companies - MNCs have to travel frequently from one country to another for attending business meetings, client visits and sales. Indians have a fascination for a foreign degree and overseas education. Over the years the number of Indian students studying in different parts of the world has increased. A large number of people travel every year to developed countries for medical treatment and many travel for spending their holidays. Most of the people travel for a short duration, ranging from a couple of days to a month. Hence, in this period it is very difficult for someone to look for a new sim card in a foreign land and wait for days to get the new connection activated. The delay creates tension among family members and friends back home and people worry about the well-being of the traveler. To solve these hassles a number of companies have started pre activated international sim card purchase business in India. The major players in this industry are: Matrix Cellular, Clay, Uniconnect, Roam 1 and Znet connect.

\section{Objectives}

1. To study the international sim card industry in India.

2. To find out the customer preferences for choosing an international sim card service provider.

\section{Research Methodology}

In order to understand the dynamics of international sim card industry both primary and secondary research was conducted. As a part of secondary research different books and journals pertaining to the telecom industry were studies and leaflets and brochures of international sim card service providers were studied. In order to find out the customer preferences and their experiences of using international sim card primary research was conducted. For this a questionnaire was developed and interviews were conducted.

\section{Sample size: 100}

Location: Kolkata. Samples were taken from the employees of IBM, ERRICSON, EXIDE, Cognizant and TCS who frequently travelled abroad.

\section{Literature Review}

According to James C. Cox in The Economic Journal, consumer economics functions on the hypothesis that consumers look for the most value or satisfaction that they can buy [1]. Hence, it is very important to continually monitor and try to develop the standards of a product so that it can create a sense of need in the customer's cognizance. As globetrotting has become very common, it is very important to find new communication options which provide good connectivity and accessibility for people all over the world. The Indian Telecom Industry has undergone huge transformation since 1991 [2]. Value added services, which included Country Specific sim card phone services, were opened to private sector in 1992. The National Telecom Policy (NTP) allowed private sectors to participate in basic services in 1994 [3]. An independent regulatory authority by the name Telecom Regulatory Authority of India (TRAI), was set up in 1997 [4]. New policices for Internet Service Providers (ISPs) was announced in 1998, thus opening the market to private sector providers. International Long Distance (ILD) Services were opened for competition in 2002. The Country Specific Sim card phone industry came into being in the mid-1990s [5]. By the end of 2002, the Indian Country Specific Sim card phone Industry had over 10 million subscribers. International sim cards gives users the freedom to travel abroad and do not bother about the international roaming charges. Some of the facilities provided for international travelers are: postpaid and prepaid sim card - Under this a local postpaid mobile number of the country is given to the customer. They receive the facility of free incoming calls and customized tariff plans and $24 \mathrm{X} 7$ customer supports is provided [6]. The postpaid customers are given the facility to check their account balance online. Customers can choose an internet pack as per their preference and access emails, browse and download applications at 1/10th the cost of International Data Roaming. The companies also provide Forex card which can be used as a debit card in order to withdraw cash and make payments. Forex cards give the benefits of instant cash in the currency

*Corresponding author: Saibal Kuamr Saha, Assistant Professor, University of Technology and Management, 4th Floor, Shillong, Meghalaya, India, Tel: 09089933991; E-mail: saibal115@gmail.com

Received May 30, 2016; Accepted July 01, 2016; Published July 10, 2016

Citation: Saha SK (2016) Jockeying for Position in International Sim Card Industry in India. Bus Eco J 7: 232. doi:10.4172/2151-6219.1000232

Copyright: (c) 2016 Saha SK. This is an open-access article distributed under the terms of the Creative Commons Attribution License, which permits unrestricted use, distribution, and reproduction in any medium, provided the original author and source are credited. 
required. They have zero transaction fees and can be used for online purchases and transactions.

Due to technological advancements, technologies like OTT VoIP (Over The Top Voice over Internet Protocol) have helped companies like Skype, Facetime and WatsApp to eat into mobile operators roaming revenue [7]. The following figure shows the global roaming revenue forecast (Figure 1).

Some of the benefits provided by the service providers are:

Postpaid SIM card [8]:

- Free incoming calls in most countries.

- Local postpaid mobile number.

- Customized Tariff Plans.

- 24x7 Customer Support.

Prepaid SIM card:

- Large savings on International Roaming bills.

- Receive number before departure.

- Avail the facility of Pay-As-You-Go.

- Easy online recharge.

- $24 \times 7$ customer care.

Internet Packs:

- Access emails, browse websites and download applications.

- Different types of data plans - customized and unlimited.

- Activate data pack before departure.

- $24 \times 7$ Customer Care Support.

Forex Card:

- Helps to get cash in the currency as desired.

- Card can be used to purchase online and perform online transactions.

- Helps to avoid forex exchange fluctuation.

- It can be reloadable anytime and anywhere.

- It helps in instant currency transfer.

Special package for corporate clients:

- Personalized account manager

- Customized tariff plans

- Special credit periods

- Bill payment in Indian currency

- $24 \times 7$ customer support

Special package for students:

- Availability of phone number before departure

- Competitive tariffs

- Billing in Indian Rupees

- Payments can be made by the family in India

- Free itemized bills

\section{Findings from the Primary Research}

\section{Travel frequency}

From the survey it was seen that bi annual travelers (44\%) was the highest which was followed by travelers who travelled once in a year (38\%). Only $2 \%$ travelled once in a month and $16 \%$ travelled once in three months (Figure 2).

\section{Purpose of visit}

Most of the respondents (43\%) travelled abroad for official purpose. Few of them (39\%) travelled for leisure and entertainment to get out of the busy life and very few people (18\%) went abroad for personal purpose barring students (Figure 3).

\section{Mode of payment}

It was observed that $45 \%$ of the custoers used credit card, $35 \%$ used cash while cheque and company undertaking payment were the least preferred mode of payments (Figure 4).

\section{Problems faced}

It was observed that most of the people (30\%) had problems with the dialing process while $18 \%$ had problems with the billing process and only $2 \%$ faced problems with the network process (Figure 5).

\section{Other services}

The survey revealed that most of the people $60 \%$ did not use any other services from the international sim card provider. 25\% used Data services, 10\% Travel Insurance and 5\% used FOREX (Figure 6).

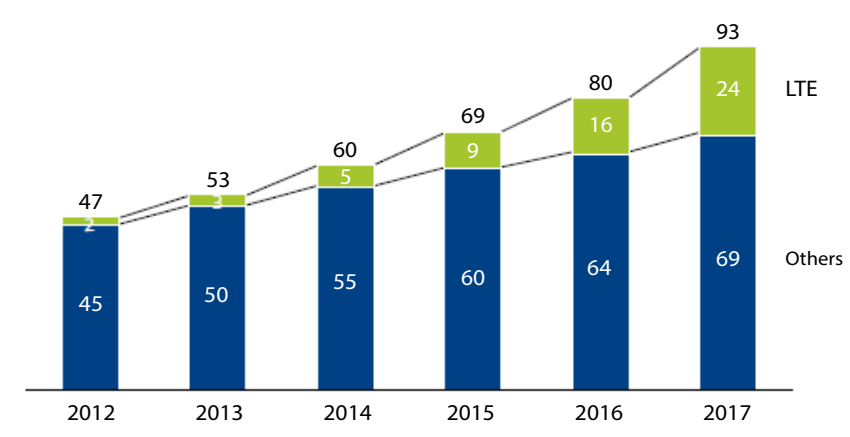

Figure 1: Global roaming revenues (LTE- Long Term Evolution vs Traditional Roaming Forecast 2012-2017, US\$ bl).

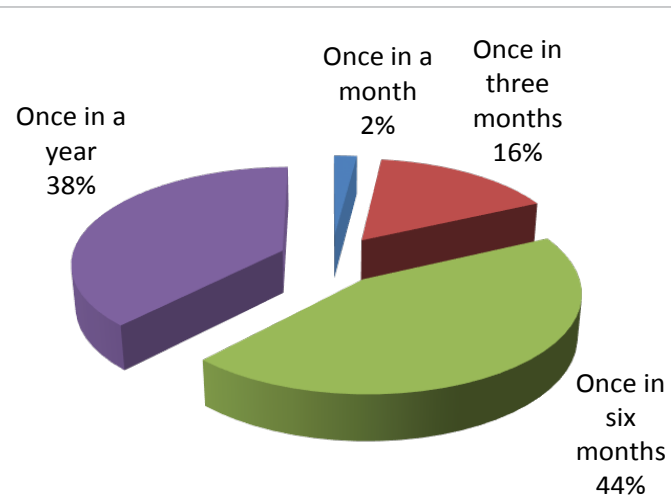

Figure 2: Travel frequency. 


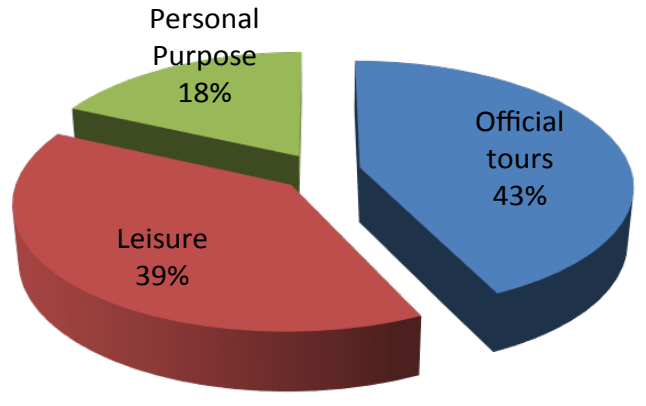

Figure 3: Purpose of visit.

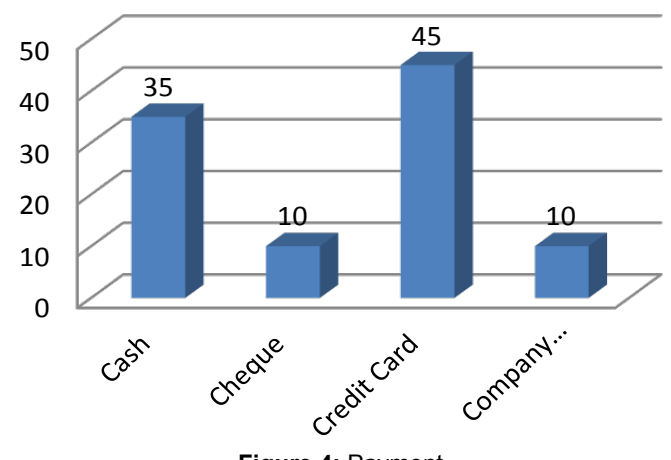

Figure 4: Payment.

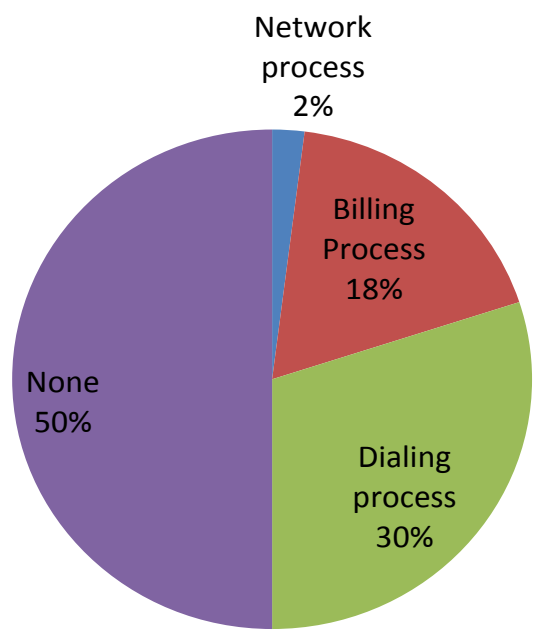

Figure 5: Problems faced.

\section{Brand awareness}

The survey data revealed that Matrix was the most popular brand (100\%) followed by One world (93\%). 52\% of the respondents knew about Uniconnect, $44 \%$ about clay and $41 \%$ about Vodafone that these were the international sim card providers in India (Figure 7).

\section{Customer preference}

It was seen that most of the respondents preferred Matrix (69\%) followed by One world (28\%) and Clay (3\%) for international sim card (Figure 8).

\section{Reasons for customer preference}

It was observed that the most important parameter for customer preference for international sim card was availability (32\%) followed by influence from peers $(25 \%)$. The brand name (23\%) was also very important followed by tariff rates (12\%) and service quality (8\%) (Figure 9).

\section{Conclusion}

After analyzing the findings of the research it can be concluded that Matrix with strong brand recognition is a market leader. Matrix Cellular is the most respected company in the telecom sector. Most
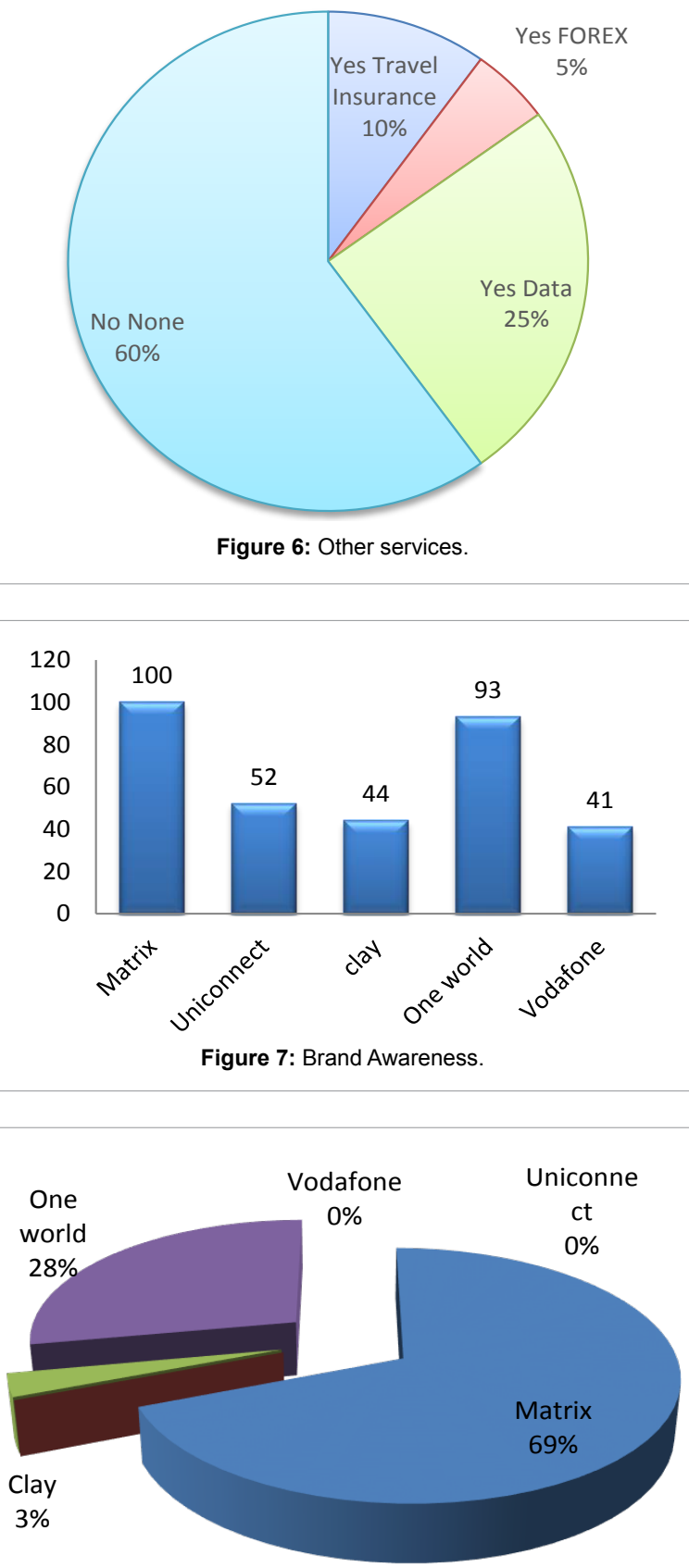

Figure 8: Customer Preference. 


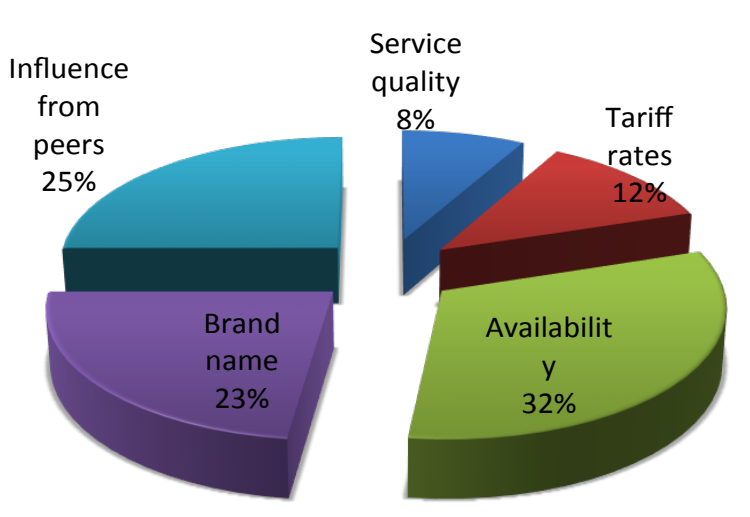

Figure 9: Reasons for customer preference.

of the subscribers on an average do not want to spend more than Rs 3000/-. Availability of the sim card and influence/recommendation from peers are very important parameters which helps customers to choose between different brands $[9,10]$. As people do not travel abroad too frequently, attractive schemes could be designed to retain the brand loyalty of the customers. Although service quality is very low in the customer preference list but this becomes very important as this parameter becomes the sole factor for influence from peers. If any customer encounters bad service quality, he/she will spread this news to his peers and this becomes a loss to the company. Hence, companies should try to provide good service quality.

\section{References}

1. James C, Lingoes, Martin P (1972) The Index of Consumer Satisfaction Methodology. Proceedings of the Third Annual Conference of the Association for Consumer Research pp: 689-712.

2. (2015) A brief report on Telocom Sector in India. ASA \& Associates.

3. (2012) Telecom Sector in India: A Decadal Profile. TRAI.

4. T. Vijayaragavan (2009) India's Telecom Industry-An Overview. Market Survey.

5. Papori B, Rashmi B (2014) Telecom Sector in India: Past, Present and Future. International Journal of Humanities \& Social Science Studies.

6. http://www.trai.com/

7. Andreas G (2014) What is the next roaming strategy for EU Operators? Delotte.

8. http://www.matrix.in

9. http://www.clay.co.in

10. http://www.uniconnect.in 